\title{
The incidence of hypophosphatemia in the early posttransplant period in renal transplant recipients and its association with graft function
}

\author{
Emel Işıktaş Sayılar®
}

Department of Nephrology, Ufuk University School of Medicine, Dr. Rldvan Ege Hospital, Ankara, Turkey

\begin{abstract}
Objectives: To investigate the prevalence of posttransplant hypophosphatemia in the early posttransplant period among renal transplant recipients in relation to its impact on renal graft function.

Methods: A total of 78 renal transplant recipients who were transplanted between January 2016 and March 2020 were included in this retrospective single center study. Data on laboratory findings (phosphate, creatinine, estimated glomerular filtration rate [eGFR], albumin, serum corrected calcium and parathyroid hormone [PTH] levels) at pre- and posttransplant 3 month follow up period were recorded.

Results: Hypophosphatemia was detected in $16(20.8 \%), 13(16.7 \%)$ and $7(9.1 \%)$ patients at the posttransplant day 10, month 1 and month 3, respectively. Posttransplant day 10 and day 30 measurements revealed significantly lower serum creatinine values $(p<0.001$ and $p<0.07$, respectively) and significantly higher eGFR values ( $p=0.009$ and $p=0.036$, respectively) in the hypophosphatemic group compared to the normophosphatemic group. Serum phosphate displayed linear relationship with creatinine at day $10(\mathrm{r}=0.687$, $p<0.001)$, day $30(\mathrm{r}=0.301, p=0.007)$, while not correlated with PTH levels at posttransplant day 10 , day 30 and day 90.

Conclusions: Our findings suggest that hypophosphatemia is common in the early posttransplant period, particularly first month after kidney transplantation, being associated with better renal graft function.

Keywords: Hypophosphatemia, kidney transplantation, graft function
\end{abstract}

$\mathrm{H}$ ypophosphatemia is a prevalent complication observed in $40-90 \%$ of renal transplant patients in the posttransplant first month [1]. In chronic kidney disease (CKD), along with a decline in eGFR, phosphaturic hormones such as parathyroid hormone (PTH) and fibroblast growth factor 23 (FGF-23) increase in response to phosphate retention and inhibit renal tubular phosphate reabsorption $[2,3]$. As kidney function recovers after kidney transplantation, the accumulated FGF-23 and PTH exaggerate renal tubular phosphate leak, leading to phosphate depletion. With normalization of PTH and FGF-23 levels toward baseline, serum phosphate levels gradually increase and reach the normal limits within 12 months [4-6].

Although hypophosphatemia is considered likely to be associated with a good graft function and prolonged graft survival, the clinical relevance of posttransplant hypophosphatemia remains unclear in terms of graft survival exact [7].

This study aimed to evaluate the relationship beassociation with graft function. Eur Res J 2021;7(5):495-500. DOI: 10.18621/eurj.802982

Address for correspondence: Emel Işıktaş Sayllar, MD., Assistant Professor, Ufuk University School of Medicine, Dr. Rudvan Ege Hospital, Department of Nephrology,06830 Balgat, Ankara, Turkey.E-mail: emelisiktas@yahoo.com, GSM: +90 507 9648090, Fax: +90 3122044266 
tween serum phosphate levels and graft function in renal transplant patients within the first 3 months of posttransplant period.

\section{METHODS}

\section{Study Population}

Seventy eight consecutive adult patients who underwent renal transplantation between January 2016 and March 2020 were included in this retrospective single center study. Inclusion criteria were receiving $\mathrm{ABO}$-compatible first-time kidney transplantation at least 1 year ago, while exclusion criteria were being under the age of 18 and history of pretransplant parathyroidectomy. There was no current or previous noncalcium-containing phosphate binder, vitamin D analog, or calcimimetic use in any of the patients.

Written informed consent was obtained from each subject following a detailed explanation of the objectives and protocol of the study which was conducted in accordance with the ethical principles stated in the "Declaration of Helsinki" and approved by the Ufuk University Faculty of Medicine Ethics Committee (Protocol no: 20200703/2).

\section{Assessments}

Data on patient demographics, clinical and laboratory findings, tacrolimus levels and follow-up records were collected from the hospital database. $\mathrm{Pa}-$ tients were followed up during the first 90 days of posttransplant period and data on routine laboratory tests (creatinine, phosphate, calcium, albumin, parathyroid hormone levels) were recorded before transplantation and on posttransplant 10th day, $1 \mathrm{st}$ month and 3rd months. Posttransplant hypophosphatemia was defined as serum phosphate level $<2.3$ $\mathrm{mg} / \mathrm{dL}$. Serum calcium was corrected based on the following equation: Corrected $\mathrm{Ca}(\mathrm{mg} / \mathrm{dL})=$ Serum Calcium $+[(4.0-$ albumin $(\mathrm{g} / \mathrm{dL})) \times 0.8)][8]$. Estimated glomerular filtration rate (eGFR) was calculated using the Modification of Diet in Renal Disease formula [9].

\section{Treatments}

When indicated anti-thymocyte globulin (ATG, Grafalon Neovii) was administered at $100 \mathrm{mg} / \mathrm{g}$ dose for 3 days. Following total $1500 \mathrm{mg}$ intravenous methyl-prednisolone, all patients were administered prednisolone $(0.8 \mathrm{mg} / \mathrm{kg} / \mathrm{day}$, orally). Prednisolone dose was tapered to $30 \mathrm{mg}$ /day at 1 month, $20 \mathrm{mg}$ /day at 2 months and $5 \mathrm{mg} /$ day after 3 months. In the maintenance treatment phase, calcineurin inhibitor [tacrolimus (Tac); $0.1 \mathrm{mg} / \mathrm{kg} /$ day, 2 doses per day] and antiproliferative agent (mycophenolate mofetil; maximum $2 \mathrm{~g}$ /day or mycophenolate sodium; maximum $1440 \mathrm{mg} / \mathrm{g}$ ) were used along with prednisolone. Tac doses were titrated as needed to achieve target blood levels. In case of acute rejection, renal biopsy was performed and treatment (pulse methyl-prednisolone, ATG, plasmapheresis, and intravenous immunoglobulin treatments alone or in combination) was administered according to Banff criteria [10].

\section{Statistical Analysis}

Statistical analysis was made using IBM SPSS Statistics for Windows, version 23.0 (IBM Corp., Armonk, NY). The Student-t test was used to compare the findings in hypophosphatemic and normophosphatemic groups for each time period. The Pearson correlation analysis was used to measure the strength of a linear association between serum phosphate and other variables and then Simple Linear Regression analysis was performed for further analysis. Data were expressed as mean \pm standard deviation (SD), median (interquartile range) and percent (\%) where appropriate. $P<0.05$ was considered statistically significant.

\section{RESULTS}

Of the patients, $21.8 \%$ were female and $78.2 \%$ were male. The mean age was $43 \pm 14$ years and median follow-up period was 28 (ranged, 15 to 40 ) months. The underlying causes of end-stage renal disease involved chronic glomerulonephritis in 32 (41\%) patients, hypertension in $17(20.8 \%)$ patients, type 2 diabetes mellitus in $12(15.4 \%)$ patients and secondary amyloidosis in $10(12.8 \%)$ patients, while nephrolithiasis, polycystic kidney disease and no detectable cause were noted in $2(2.6 \%), 2(2.6 \%)$ and $3(3.8 \%)$ patients, respectively. During follow-up, acute allograft rejection occurred in $16(20.5 \%)$ patients. Dialysis type, number of tissue adaptation, type of transplantation, type of induction and maintenance immunosuppression treatment features are shown in Table 1.

The mean pretransplant phosphate level was $4.2 \pm$ 
Table 1. Patient demographics and baseline characteristics

\begin{tabular}{|c|c|}
\hline Variables & $n=78$ \\
\hline Gender, F/M, n (\%) & $17 / 61(21.8 / 78.2)$ \\
\hline Age, (year, mean \pm SD) & $43 \pm 14$ \\
\hline \multicolumn{2}{|l|}{ Type of dialysis, $\mathrm{n}(\%)$} \\
\hline Preemptive & $40(51.3)$ \\
\hline Hemodialysis & $37(47.4)$ \\
\hline Peritoneal dialysis & $1(1.3)$ \\
\hline Transplant type (live/cadaver) & $75 / 3(96.2 / 3.8)$ \\
\hline \multicolumn{2}{|l|}{ Miss-Match count, $\mathrm{n}(\%)$} \\
\hline $0 \mathrm{MM}$ & $3(3.8)$ \\
\hline $1 \mathrm{MM}$ & $7(9.0)$ \\
\hline $2 \mathrm{MM}$ & $10(12.8)$ \\
\hline $3 \mathrm{MM}$ & $26(33.3)$ \\
\hline $4 \mathrm{MM}$ & $14(17.9)$ \\
\hline $5 \mathrm{MM}$ & $9(11.5)$ \\
\hline $6 \mathrm{MM}$ & $9(11.5)$ \\
\hline Transplant duration (month, median, IQR) & $28(15-40)$ \\
\hline \multicolumn{2}{|l|}{ Induction treatment, $\mathrm{n}(\%)$} \\
\hline ATG & $34(43.6)$ \\
\hline None & $44(56.4)$ \\
\hline \multicolumn{2}{|l|}{ Maintenance treatment } \\
\hline $\mathrm{Tac}+\mathrm{MMF}$ & $61(78.2)$ \\
\hline Tac + MFA & $17(20.8)$ \\
\hline Acute rejection, $\mathrm{n}(\%)$ & $16(20.5)$ \\
\hline
\end{tabular}

$1.37 \mathrm{mg} / \mathrm{dL}$, which decreased to $3.2 \pm 1.01 \mathrm{mg} / \mathrm{dL}, 3.2$ $\pm 0.86 \mathrm{mg} / \mathrm{dL}$, and $3.4 \pm 0.70 \mathrm{mg} / \mathrm{dL}$ at the posttransplant day 10, month 1 and month 3, respectively. Hypophosphatemia was detected in $16(20.8 \%), 13$ $(16.7 \%)$ and $7(9.1 \%)$ patients at the posttransplant day 10 , month 1 and month 3, respectively. Mean posttransplant levels of creatinine significantly decreased to $1.65 \pm 1.10 \mathrm{mg} / \mathrm{dL}, 1.37 \pm 0.60 \mathrm{mg} / \mathrm{dL}$, and $1.39 \pm$ $0.43 \mathrm{mg} / \mathrm{dL}$ at the posttransplant day 10 , month 1 and month 3, respectively. The mean pretransplant PTH level was $418.14 \pm 400.75 \mathrm{ng} / \mathrm{L}$ and decreased to $184.55 \pm 135.38 \mathrm{ng} / \mathrm{L}, 202.46 \pm 132.66 \mathrm{ng} / \mathrm{L}$, and $134.31 \pm 95.62 \mathrm{ng} / \mathrm{L}$ at the posttransplant day 10 , month 1 and month 3, respectively. When compared to pre-transplant laboratory parameters, significant dif- ference was noted in post-transplant parameters for 10th day, 1 st month and 3rd month $(p<0.05)$ (Table 2).

Posttransplant day 10 and day 30 measurements revealed significantly lower serum creatinine values ( $p<0.001$ and $p<0.07$, respectively) and significantly higher eGFR values $(p=0.009$ and $p=0.036$, respectively) in the hypophosphatemic group compared to the normophosphatemic group (Table 3, Fig. 1 and Fig. 2).

Serum phosphate displayed linear relationship with creatinine at day $10(\mathrm{r}=0.687, p<0.001)$, day $30(\mathrm{r}=0.301, p=0.007)$ and day $90(\mathrm{r}=0.070, p=$ $0.548)$ and inverse relationships with eGFR at day 10 $(\mathrm{r}=-0.461, p<0.001)$, day $30(\mathrm{r}=-0.157, p=0.171)$ 
Table 2. Laboratory parameters before and after transplantation

\begin{tabular}{lcccc}
\hline \multicolumn{3}{c}{ Pretransplant } & Posttransplant \\
\hline Variables, mean \pm SD & Day -1 & Day +10 & Day +30 & Day +90 \\
$\mathrm{P}(\mathrm{mg} / \mathrm{dL})$ & $4.2 \pm 1.37$ & $3.2 \pm 1.01$ & $3.2 \pm 0.86$ & $3.4 \pm 0.70$ \\
$\mathrm{Cr}(\mathrm{mg} / \mathrm{dL})$ & $4.62 \pm 1.62$ & $1.65 \pm 1.10$ & $1.37 \pm 0.60$ & $1.39 \pm 0.43$ \\
$\mathrm{eGFR}\left(\mathrm{ml} / \mathrm{min} / 1.73 \mathrm{~m}^{2}\right)$ & $15.39 \pm 5.69$ & $60.26 \pm 25.59$ & $67.33 \pm 22.24$ & $67.24 \pm 23.83$ \\
$\mathrm{c}-\mathrm{Ca}(\mathrm{mg} / \mathrm{dL})$ & $9.89 \pm 0.64$ & $9.63 \pm 0.89$ & $9.73 \pm 0.43$ & $9.53 \pm 0.89$ \\
$\mathrm{PTH}(\mathrm{ng} / \mathrm{L})$ & $418.14 \pm 400.75$ & $184.55 \pm 135.38$ & $202.46 \pm 132.66$ & $134.31 \pm 95.62$ \\
\hline
\end{tabular}

Data are shown are mean \pm standard deviation. $\mathrm{c}-\mathrm{Ca}=$ corrected calcium, $\mathrm{Cr}=$ creatinine; eGFR $=$ estimated glomerular filtration rate, $\mathrm{P}=$ phosphate; $\mathrm{PTH}=$ parathyroid hormone

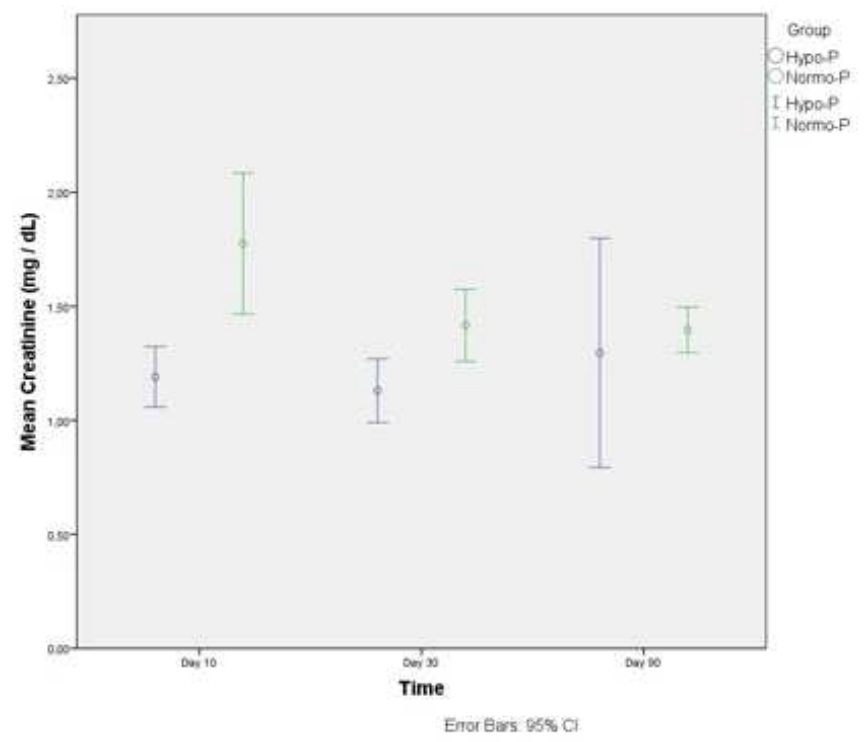

Fig. 1. Comparison of posttransplant creatinine values of hypophosphatemic and normophosphatemic groups.

and day $90(\mathrm{r}=-0.013, p=0.911)$. No significant correlation was noted between serum phosphate and $\mathrm{PTH}$ levels at day $10(\mathrm{r}=-0.134, p=0.416)$, day $30(\mathrm{r}=$ $0.262, p=0.163)$ and day $90(\mathrm{r}=-0.184, p=0.388)$.

\section{DISCUSSION}

In the early posttransplant stage, the relatively high FGF-23 and PTH concentrations in relation to restored renal excretory capacity of phosphate may result in hypophosphatemia, especially within the first year [11]. In a past study by Ghorbani et al. [5] in 50 kidney transplant patients, hypophosphatemia was reported in $42 \%$ of patients in the first posttransplant month. In the current study, hypophosphatemia was

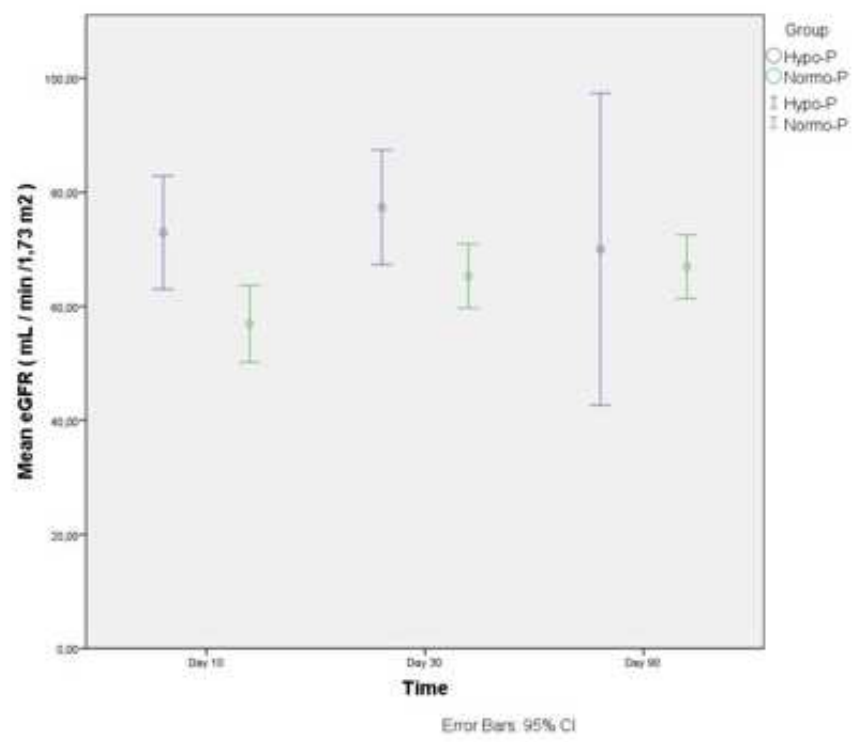

Fig. 2. Comparison of posttransplant eGFR values of hypophosphatemic and normophosphatemic groups.

noted in $13(16.7 \%)$ patients in the in the first posttransplant month.

Our findings related to association of the development of hypophosphatemia with a lower creatinine and higher eGFR values seems to be in accordance with consideration of good graft function to be accompanied by an increased renal capacity to excrete phosphate in early after transplantation. Identification of lower creatinine levels and higher eGFR values in our hypophosphatemic patients than in normophosphatemic patients at posttransplant day 30 indicates an inverse correlation between serum phosphate levels and kidney function. Likewise, in a past study by Seifi et al. [12] with 237 transplant patients, hypophosphatemia was reported in $58 \%$ of patients within the first 2 months of the posttransplant period, while au- 


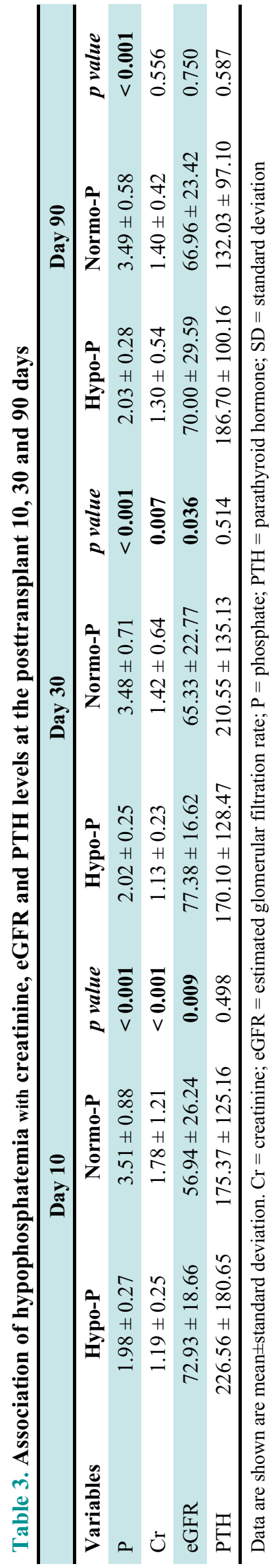

thors also noted significantly lower serum creatinine levels in hypophosphatemic vs. normophosphatemic patients [12]. In a past study among 90 renal transplant patients, presence of hypophosphatemia at the posttransplant first month and 3rd month but not at the posttransplant 12th month was reported to be an independent predictor of good kidney survival [3].

Elevated PTH levels before transplantation have been shown to decline during the first 3 months after kidney transplantation. High PTH levels can be observed in $30-60 \%$ of kidney transplant recipients with good allograft function in the 1st year after kidney transplantation. PTH production cannot reduce instantly after kidney transplantation, and along with the increase in eGFR, the sudden change in the definition of hyperparathyroidism may complicate the interpretation [13]. Similar to our findings, there studies in the literature indicated no significant difference between normo- and hypophosphatemic patients in terms of PTH levels [5, 14]. Bhan et al. [15] reported that pretransplant PTH elevation was not a risk factor for posttransplant hypophosphatemia, while FGF-23 levels were independently associated with decreased serum phosphate levels. In the current study, since FGF-23 levels were not measured, the association between FGF-23 levels and posttransplant hypophosphatemia could not be analyzed.

The high-dose steroids and tacrolimus are considered to be associated with renal phosphate wasting. However, while hypophosphatemia is commonly noted after kidney transplantations, it does not typically develop after other solid organ transplants despite use of similar and often higher doses of immunosuppressive regimens [16, 17]. In the current study, while almost all patients were on an identical immunosuppressive regimen, only some patients developed hypophosphatemia. Accordingly, immunosuppressive agents, whilst may induce phosphaturia after renal transplantation, seem unlikely to be the primary cause of hypophosphatemia.

\section{Limitations}

The major limitations of the current study seem to be the small sample size and lack of data on FGF-23 levels, 25(OH)D vitamin levels and fractional phosphate excretion at pre- and post-transplant period as well as on the dietary phosphate intake. 


\section{CONCLUSION}

In conclusion, hypophosphatemia is frequently seen after renal transplantation in relation to the functional performance of the transplanted kidney. Our data also suggest that the impact of hypophosphatemia on graft survival is influenced by the time after kidney transplantation. Further prospective, larger scale, controlled and multicenter cohort studies are needed to investigate the prevalence of hypophosphatemia in the early posttransplant period and its correlation with graft function.

\section{Authors' Contribution}

Study Conception: EIS; Study Design: EIS; Supervision: EIS; Funding: EIS; Materials: EIS; Data Collection and/or Processing: EIS; Statistical Analysis and/or Data Interpretation: EIS; Literature Review: EIS; Manuscript Preparation: EIS and Critical Review: EIS.

\section{Conflict of interest}

The authors disclosed no conflict of interest during the preparation or publication of this manuscript.

\section{Financing}

The authors disclosed that they did not receive any grant during conduction or writing of this study.

\section{REFERENCES}

1. Huber L, Naik M, Budde K. Frequency and long-term outcomes of post-transplant hypophosphatemia after kidney transplantation. Transpl Int 2013;26:94-6.

2. Sirilak S, Chatsrisak K, Ingsathit A, Kantachuvesiri S, Sumethkul V, Stitchanrtakul W, et al. Renal phosphate loss in long-term kidney transplantation. Clin J Am Soc Nephrol 2012;7:323-31.

3. Nakai K, Mitsuiki K, Kuroki Y, Nishiki T, Motoyama K, Nakano T, et al. Relative hypophosphatemia early after transplantation is a predictor of good kidney graft function. Clin Exp Nephrol 2019;23:1161-8.

4. Kawarazaki H, Shibagaki Y, Fukumoto S, Kido R, Ando K, Nakajima I, et al. Natural history of mineral and bone disorders after living-donor kidney transplantation: a one-year prospective observational study. Ther Apher Dial 2011;15:481-7.

5. Ghorbani M, Ossareh S. Early postkidney transplantation hypophosphatemia. J Res Med Sci 2020;25:36.

6. Evenepoel P, Meijers BK, de Jonge H, Naesens M, Bammens B, Claes K, et al. Recovery of hyperphosphatoninism and renal phosphorus wasting one year after successful renal transplantation. Clin J Am Soc Nephrol 2008;3:1829-36.

7. Benavente D, Chue CD, Moore J, Addison C, Borrows R, Ferro CJ. Serum phosphate measured at 6 and 12 months after successful kidney transplant is independently associated with subsequent graft loss. Exp Clin Transplant 2012;10:119-24.

8. Ketteler M, Block GA, Evenepoel P, Fukagawa M, Herzog CA, McCann L, et al. Diagnosis, Evaluation, Prevention, and Treatment of Chronic Kidney Disease-Mineral and Bone Disorder: Synopsis of the Kidney Disease: Improving Global Outcomes 2017 Clinical Practice Guideline Update. Ann Intern Med 2018;168:422-30.

9. Levey AS, Stevens LA, Schmid CH, Zhang YL, Castro AF, Feldman $\mathrm{H}$, et al. A new equation to estimate glomerular filtration rate. Ann Intern Med 2009;150:604-12.

10. Solez K, Colvin RB, Racusen LC, Haas M, Sis B, Mengel M, et al. Banff 07 classification of renal allograft pathology: updates and future directions. Am J Transplant 2008;8:753-60.

11. van Londen M, Aarts BM, Deetman PE, van der Weijden J, Eisenga MF, Navis G, et al. Post-transplant hypophosphatemia and the risk of death-censored graft failure and mortality after kidney transplantation. Clin J Am Soc Nephrol 2017;12:130110.

12. Seifi S, Pezeshki ML, Khatami MR, Mazdeh MM, Ahmadi F, Maziar S. Post-renal transplantation hypophosphatemia. Transplant Proc 2003;35:2645-6.

13. Taweesedt PT, Disthabanchong S. Mineral and bone disorder after kidney transplantation. World J Transplant 2015;5:231-42. 14. Prasad N, Jaiswal A, Agarwal V, Kumar S, Chaturvedi S, Yadav S, et al. FGF23 is associated with early post-transplant hypophosphataemia and normalizes faster than $\mathrm{PTH}$ in living donor renal transplant recipients: a longitudinal follow-up study. Clin Kidney J 2016;9:669-76.

15. Bhan I, Shah A, Holmes J, Isakova T, Gutierrez O, Burnett SM, et al. Post-transplant hypophosphatemia: Tertiary 'HyperPhosphatoninism'? Kidney Int 2006;70:1486-94.

16. Falkiewicz K, Nahaczewska W, Boratynska M, Owczarek H, Klinger M, Kaminska D, et al. Tacrolimus decreases tubular phosphate wasting in renal allograft recipients. Transplant Proc 2003;35:2213-5.

17. Ninkovic M, Skingle SJ, Bearcroft PW, Bishop N, Alexander GJ, Compston JE. Incidence of vertebral fractures in the first three months after orthotopic liver transplantation. Eur J Gastroenterol Hepatol 2000;12:931-5. 